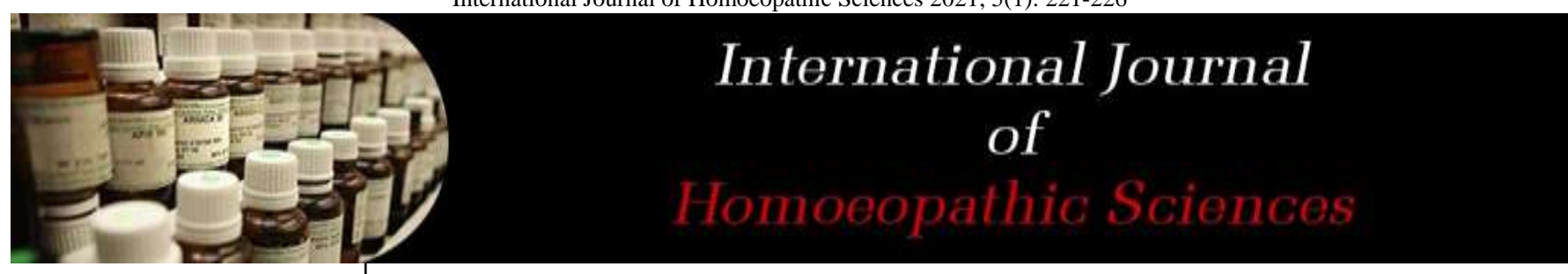

E-ISSN: $2616-4493$ P-ISSN: 2616-4485 www.homoeopathicjournal.com IJHS 2021; 5(1): 221-226 Received: 17-11-2020 Accepted: 28-12-2020

Dr. M Gnnanaprakasham Assistant Professor,

Department of Psychiatry, National Homoeopathy Research Institute in Mental Health, Kottayam, Kerala, India

Dr. S Brundha Part - I - PG Scholar, Department of Psychiatry, National Homoeopathy Research Institute in Mental Health, Kottayam, Kerala, India

Corresponding Author: Dr. M Gnnanaprakasham Assistant Professor, Department of Psychiatry, National Homoeopathy Research Institute in Mental Health, Kottayam, Kerala, India

\section{Homoeopathic portrait of conduct disorder}

\section{Dr. M Gnnanaprakasham and Dr. S Brundha}

DOI: $\underline{\text { https://doi.org/10.33545/26164485.2021.v5.i1d.318 }}$

\begin{abstract}
Conduct disorder is characterized by a repetitive and protracted pattern of dissocial, aggressive and defiant behaviour. These may lead to the development of antisocial behavior which proceeds to the violation of the social norms. The conduct disorder in its progress towards adolescents express certain abnormal behavior patterns like involving in theft, curiosity to take substance's or drugs, impulse to indulge in unsafe sex, perverted sexual behavior, mood swings and other personality disorders. The conventional system of medicine will helpto manage impulsivity and in extreme mood swings. The Homoeopathic case taking, analysis of the case and understanding of the person's individualistic personality will be helpful in bringing the behavioral change in vast areas like curiosity, impulsivity, destructiveness, violence, distractibility and overall general well being of the patient. Considering the most frequently reported symptoms and as per DSM V criteria's, the expression of conductdisorder has been converted into reportorial rubricswhich provided agroup of remedies that may be help to manage the persons with conduct disorder. Homoeopathic medicines like Hyos, Nux-vom, Bell, Stram, Sulph, Taren, Staphy, Plat, Lach, Verat were found to be probably indicated medicines in the view of symptomatology of conduct disorder.
\end{abstract}

Keywords: Conduct disorder, DSM V symptomatology, radar 10, homoeopathy medicines

\section{Introduction}

Among the children, Aggressive patterns of behavior are the most frequent rationale to be referred for psychiatric intervention. Even though the behavior is developmentally normal in children the pharmacological intervention is required for those who continue to display excessive patterns of aggression and violating social or cultural norms.

Conduct disorder is one among the child psychiatric disorder which expressed as an aggressive pattern of behavior that evolves usually characterized by aggression and violation of the rights of others. According to DSM V three persistent behavior among 15 behaviors which is listed under the following four categories namely 1) Physical aggression or threats of harm to people 2) Destruction of their property or that of others 3) Thefts or acts of deceit 4) Frequent violation of age- appropriate rules, presented at least for the period of past 12 months and also atleast one 1 criteria present in the past 6 months.

Reem M. Ghandour et al., estimates the prevalence that $7.4 \%$ (approximately 4.5 million) had a behavior or conduct problem with vulnerability in boys was more than twice in girls and attain peakin middle childhood of age $6-11$ years. It is also observed in the study that children of $40 \%, 48 \%$, and $13 \%$ of children were rated as mild, moderate and severe intensity of CD respectively ${ }^{[2]}$. These antisocial behavioris due to co-existing biological factors mainly genetic influence, warmer parent - child relationship and those having shared environment on childhood conduct problems ${ }^{[3,4]}$. The co- morbidity of conduct disorder is depression, personality disorder which is more common in girls than in boys with conduct disorder ${ }^{[5]}$. Along with aggression, there is oppositionality and impulsivity with attention deficit or hyperactivity and there is a high risk of drug use in the adult those who are diagnosed as a conduct disorder at their childhood ${ }^{[6,7]}$. The stronger predictor of the outcome of anti- social behavior is based on its behaviors under the four categories of diagnostic criteria's of conduct disorder and those with physically aggressive behaviors may lead to the development of the life course persistent antisocial behavior ${ }^{[8]}$.

\section{DSM 5 diagnostic criteria}

According to DSM V, Violation of societal norms and rules, as a repetitive and persistent pattern of atleast 3followingbehaviors within the 4 domains of 1) Physical aggression or threats of harm to people 2) Destruction of their property or that of others 3) Thefts or acts of deceit 4) Frequent violation of age-appropriate rules, for the past 12 months and minimum 1 behavior for the past 6 months. 
Children frequently involved in behavioral changes like bullies, threatens or intimidates others, physical fights, has used a weapon that cause serious physical harm to others, had caused physical cruel to people and animals, has stolen by confronting a victim, has instigated others into sexual activity, destroying others property by setting the fire and other techniques (other than fire setting), has broken other's building, car etc., telling lies to obtain favors, has stolen without confronting a victim, before 13 years of age staying away from home at night against parental prohibitions and truant from school, has run away from home overnight atleast twice while residing in the parental or surrogate home are diagnosed as conduct disorder.

\section{Subtypes of conduct disorder in DSM V}

DSM-5 distinguishes childhood-onset and adolescent-onset subtypes of $\mathrm{CD}$. The differentiating characteristic is the presence of at least one symptom of CD before the age of 10 in childhood - onset conduct disorder.

\section{With limited prosocial emotions}

The individual must have minimum of two of subsequent characteristics persistently over a minimum of 12 months and in various settings.

Lack of remorse or guilt: Never feel guilty about something wrong done by them and there is a general lack of concern about the consequences of their actions

Callous-lack of empathy: The person's concern regarding the effects of their actions on them and neglecting the feelings of others though it results in profound harm to others.

Unconcerned about performance: Never concern about the poor/problematic performance at school, at work, or in other important activities.

Shallow or deficient affect: Their emotions seem to be shallow, insincere, or superficial or to obtain gain they express these emotions.

\section{Risk factors}

Paul J Frick et al., in the study conducted to identify the developmental pathway to conduct disorder has been proposed the risk factors into dispositional and contextual.

\section{Dispositional / Developmental risk factors}

As the term dispositional indicates the cause of the behavior is due to internal characteristics of a person rather than to outside force, risk factors such as temperament of the child are noticed to restlessness, impulsivity (tendency to hurt others like beating, biting, striking others), favors dangerous and novel activities (sets fire deliberately to hurt others, running away from home), poor intelligence, poor academic achievement and birth complications.

\section{Contextual risk factors}

Contextual refers to relating the circumstances that form the setting for an event or behavior. It includes the factors that related to environment like neglect, lack of parents, inadequate parental supervision, low-income and peer rejection ${ }^{[9]}$.

\section{Psychosocial risk factors}

The strongest predictor of antisocial behaviors are those who have fulfilled the behaviors under 4 criteria like stealing, destruction of property, early sexual intercourse (childhood - onset conduct disorder) and aggression and violence are at the highest risk of developing delinquency. ${ }^{10,11}$ The major contribution of psychosocial risk factors are problematic family, poor supervision, reduced emotional warmth and neglect, negative attitude towards the child leads to the attachment with other youths who are involving in delinquency ${ }^{[12,13]}$.

\section{Clinical features}

The most common clinical expressions mentioned in DSM $\mathrm{V}$ are

\section{Aggression to people and animals}

1. Frequently involved in bullies, threatens or intimidates others.

2. Starts physical fights frequently.

3. Had caused serious physical harm to others with the help of weapons.

4. Physical cruel to people.

5. Physical cruel to animals.

6. Has stolen by confronting a victim.

7. Has instigated others into sexual activity.

\section{Destruction of property}

8. Intention of causing serious damage by setting fire.

9. Has destroyed other's property intentionally (other than fire setting)

\section{Deceitfulness or theft}

10. Has broken into someone else's house, building or car.

11. Telling lies to obtain favors.

12. Has stolen items without confronting a victim.

\section{Serious violations of rules}

13. Stays out at night before 13 years though there is parental control

14. Has run away from home at least twice while living with parents.

15. Traunt from school beginning before age 13 years ${ }^{[14]}$.

\section{Pathogenesis}

The fetuses of both male and females are exposed to androgens, estrogens, and progesterone from their gonads as well as from their adrenal glands, placenta, and maternal system, yet the amount of testosterone to which the sexes are exposed varies. Oestrogen is frequently a be-friend stress response in females and testosterone is a fight or flight response in males ${ }^{[15]}$. As MAOA - L is prominent in males with low levels and serotonin with higher levels during brain development and those who were subjected to maltreatment such as maternal rejection, physical abuse are more likely to have engaged in aggressive behavior in conduct disorder ${ }^{[16,17]}$.

Abnormalities are noticed predominantly in the bilateral amygdala, right striatum, bilateral insula and left medial/superior frontal gyrus and left precuneus. The frequently affected areas are limbic structures and the anterior cingulate and orbitofrontal areas of the prefrontal cortex with those individual who are diagnosed as conduct disorder ${ }^{[18]}$. In a study conducted by Graeme Fairchild et al. 
it has been proved that the reduction in the Gray matter volume has been observed in early onset conduct disorder and additionally it has also been observed in adult onset conduct disorder ${ }^{[19]}$.

\section{Assessment tools}

Achenbach System of Empirically Based Assessment (ASEBA), is helpful in assessment of CD i.e., the Child Behavior Checklist (CBCL), the Youth Self-Report (YSR), and the Adult Self-Report (ASR).The conduct problem scales of the CBCL and YS Rare supported the identical set of things which differs within ${ }^{[20]}$. Paterson et al.; measured the externalizing problem using CBCL, YSR, and ASR which is theoretical and empirical support in construct validity and invariance hence these measurements needs time to examine their accuracy ${ }^{[21]}$.

Jan K. Buitelaar et al. Used and recommended the use of Achenbach scales CBCL, TRF, YSF; SDQ scales and Conners scales ${ }^{[22]}$. Temperament scales can also be utilized in cases where the portrait of $\mathrm{CD}$ is poorly expressed.

\section{Management}

The symptomatic management of aggression, impulsivity and co morbidities of conduct disorders like ADHD needs pharmacotherapy. Risperidone was found superior in reducing aggression. Patients treated with lithium suffered from extra pyramidal side-effects. Few trials with valproate have shown that it is effective for Conduct Disorder. Overall, there is limited evidence in treating aggression, impulsivity and co morbidities of conduct disorders yet a complete holistic management of conduct disorder is in evident regarding the role of pharmacotherapy in Conduct Disorder ${ }^{[23,24]}$.

Mairead Furlong et al. Conducted a study on Behavioral and Cognitive - Behavioral group based parenting program for early onset conduct problems which are found to be effective for improving child conduct disorder and positive parental skill in short term period. Other non pharmacological treatment are Contingency Management Treatment, Parent Management Training, Cognitive
Behavioural Skill straining, Community Based Intervention were found to be effective in the management of $\mathrm{CD}^{[25,26]}$.

\section{Homoeopathic approach}

Homoeopathy, the science and art of therapeutic medication has double existence as an institution and in the personnel of its loyal representative of the individual. With these existences, homoeopathy approaches every case, systematically from a particular and mental point of view ${ }^{\text {[27] }}$ There are poor or no previous studies / case reports in Homoeopathy published in CD. Considering the poor effectiveness of conventional medicine, which also hinders the developmental and normal functioning of brain biology and biochemistry leading to impaired brain growth of the child Homoeopathy has preferred due to its vast advantage in improvement of the person in every aspects and without any adverse reactions. According to Hahnemann, mental disease belonging to one - sided disease with psoric origin. He categorized mental disease into 4 categories which is psychosomatic (Aph 215), acute onset (Aph 221), Doubtful origin (Aph 224), and somatopsychic (Aph 225) ${ }^{[28]}$. In many research studies it has been found that the conduct disorder is developed due to poor supervision or neglect of the child in the family. Under Hahnemanian classification it falls under the category of mental disease dueto doubtful origin. Based on the clinical picture the Conduct Disorder under the three category of aggression, destruction and deceitfulness/theft, the rubrics had been formulated and repertorised to find the probable remedies. However the final remedy may vary based on the constitutional picture of the case and individuality. These remedies may be used in case of poor details of case informations to arrive at the constitutional picture.

Schroyens F. synthesis 9.0 English (SE 90), using RADAR repertory program version 10 has been used to repertorise the symptoms of $\mathrm{CD}$. Based on the symptoms mentioned under 4 categories of DSM V i.e aggression to people and animals, destruction of property, deceitfulness or theft, a serious violation of rules, the rubrics were selected.

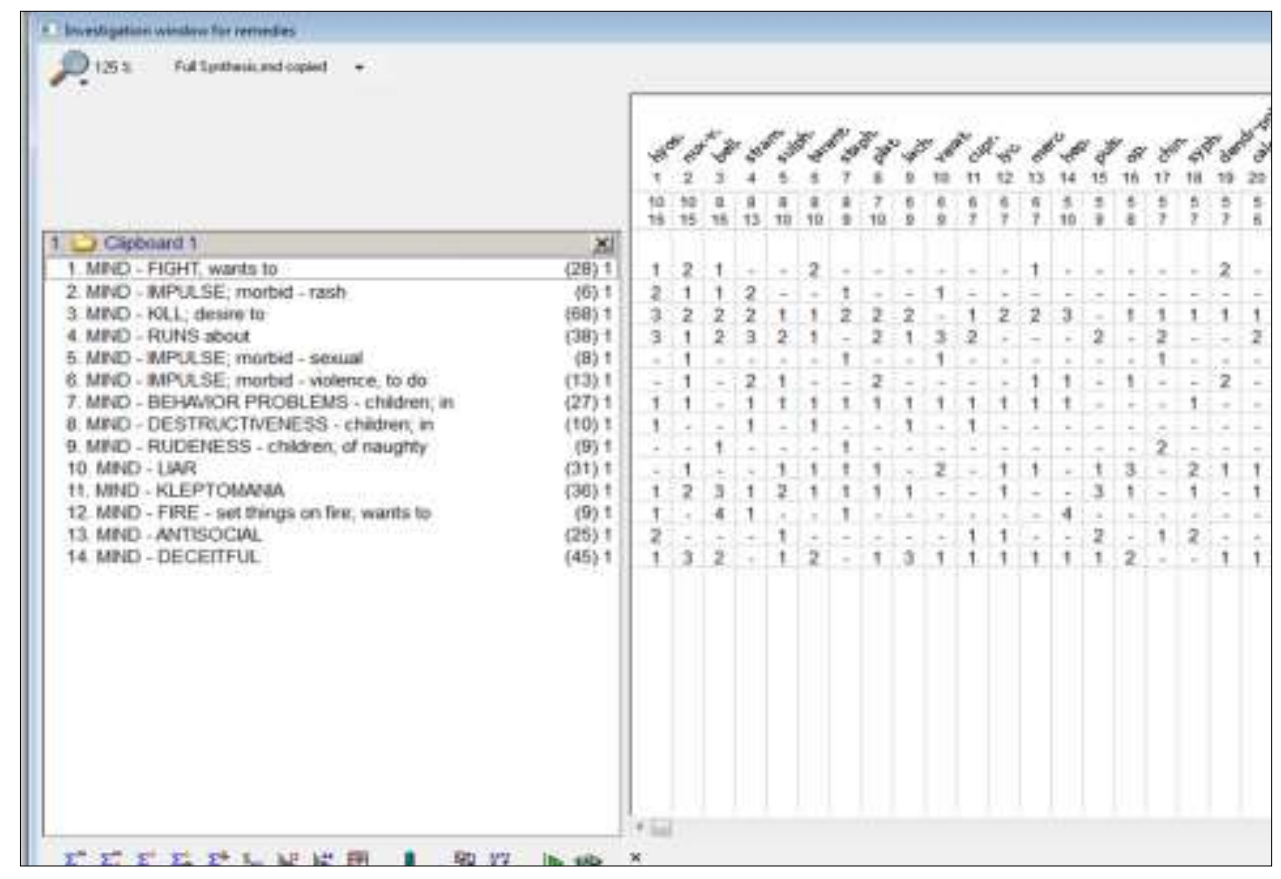

Fig 1: Investigation window for remedies 


\section{Homoeopathic Remedies}

The group of homoeopathic medicines identified based on direct rubric selection were Hyoscyamus, Nux-vomica, Belladona, Stramonium, Sulphur, Tarentula, Staphysagria, Platina, Laches is, Veratrum album etc..,

As Hahnemann explained in aph 221 that the sudden outbreak of acute mental disease can be managed well by Bell, Stram, Hyoscyamus in highly potentized minute doses the same has been derived in the above repertorisation.

As most of the symptoms of conduct disorder are covered with drugs like Bell, Hyos, Stramonium belonging to solanaceae family, the theme of the drugs among these family is that it predominantly affects the brain and it over stimulates the sympathetic nervous system producing fight and flight (violence, beating, tearing, throwing) type of reaction ${ }^{[29]}$. The portrait symptoms of the probable remedies like Hyoscyamus, Belladonna, Stramonium, Tarentula, Nux. Vom, Verat. alb ${ }^{[30,31]}$. Were summarized as follows

\section{Remedy: Hyoscyamus}

Hyoscyamus child is notorious for talking excessively especially about sexual topics, singing amorous songs. Adapted to children with hyperactivity and disruptive, during contradiction child lashes out violently and beats other people, running from the room, tears the clothes and prone to swear. The child belonging to this drug gathering their clothes under the arm to expose or fumbles their genitals in the consultation room. Cries especially on the slightest touch even in stupor, feigning in order to play a sick role.

Hyoscyamus commonly known as Henbane or Hog bane disturbs the mind, brain and nervous system predominantly. Suited to persons of sanguine temperament, those who are irritable, nervous, and hysterical. It is suitable to a mania of quarrelsome and obscene character as some diabolic forces seems to take possession of the brain preventing its functions. Very talkative, uncovering genitals, jealous, afraid of being poisoned. Marked features are convulsions, trembling, jerks, twitching cramps. Generally the complaints are worse at night, during menses, after eating, when lying down. Better by stooping. Antidotes Bell and Camph.

\section{Remedy: Belladonna}

Belladona contains alkaloids which have antiinflammatory, anti-cholinergic, antispasmodic, mydriatric, anticonvulsant, analgesic and antimicrobial activities used for treatment of various disease including urethral stent pain, myocardial ischemia injury, acute encephalitis syndrome, irritable bowel syndrome. In the recent study on evidence- based systemic review of Belladonna, included 20 studies of evidence based systemic review found treatment using belladonna is safe and effective ${ }^{[32]}$. Bell is a notorious children's remedy because the child is more intelligent and plethoric persons, when well they are jovial but becomes violent when sick. Restless child and talks fast, biting, striking, spits on faces of other people, apprehension and inclination to run away with desire to escape.

Deadly nightshade acts upon the nervous system with which it produces active congestion, twitching, convulsions, perverted special senses and pain. It is indicated for violence of attack as belladonna acts on brain causes furious excitement with sudden onset. It has marked action upon vascular system, skin and glands. It is associated with hot, red skin, face flushed with glaring eyes, throbbing carotids, excited mental state, delirium, restless sleep, hyper aesthesia of all senses, convulsive movements, aversion to water though mouth and throat is dry. Generally the complaints are worse by touch, jar, noise, draught, after noon, lying down. Better by semi-erect. Belladonna is complementary towards calc.

\section{Remedy: Stramonium}

Stramonium children will bite, gauge and stab, purposeless hyperactive in school, they distract themselves and other children. Destructiveness of all kinds - especially focuses on others and external objects. The acts include striking, tearing, shrieking, especially smashing things with superhuman strength and stamina. Child also experience terrible night terrors and screams at night. Child expresses fear of dark, tunnels or closed places, colors red and black, dogs, large body of water, cemeteries.

Common name of stramonium is Thorn apple or Datura seems to acts on brain producing marked and persistent disorder of mental faculty, hallucinations, fixed notions, terrifying delirium. It is a remedy of Terrors. Increases the mobility of the muscles of expression and of locomotion. The movements may be graceful, rhythmic or disorderly, of head and arms. It reduces spasmodic movements, and restores suppressed excretions in several cases in which absence of pain is the prominent symptom. The most common forms of mania expressed in stramonium are nymphomania of lying -in women, religious monomania in exaggerated and ridiculous scruple of conscience.

Generally the complaints are worse in dark room, when alone, looking at bright or shining objects, after sleep, on swallowing and better, from bright light, company, warmth. Stramonium antidotes: Bell and Nux-v.

\section{Remedy: Nux Vomica (Loganaceae)}

Childrens who have the impulse to kick animals and cruelty to humans. In sexual sphere the behavior of Nux. Vomica child is out of control which ends in impulsive acts. At school the childish impatient and irritable, particularly with others, scolding and reproaching others over minor incidents. It is a male remedy. The core of the drug is irritable, affects nervous system, hypersensitive and over impressionable, disposed to malicious, cruel, violent, quarrelsome, and spiteful. Adapted to thin, spare, quick, active, nervous and irritable child. It is also indicated in adults who practice a sedentary life as prolonged paperwork, over study, business persons. To scale back their work pressure, they enjoys sedative drugs like opium etc., as a result they suffer from digestive disturbance, portal congestion and hypochondrical states. Generally nuxvomica complaints worse by mental exertion, morning, after eating, Slightest touch, spicy food, stimulants, narcotics items, dry weather, cold. Better, from a nap, if allowed to end it, in evening, while at rest, in damp, wet weather, strong pressure. Antidotes: Coff, Ign, Cocc. Inimical to Zinc.

\section{Remedy: Tarentula (Araneideae)}

Suited to restless children who had boundless energy and compelled to be busy, to act. In second stage of illness in child loses control and becomes destructive as Tears his clothes or break things particularly violence is directed at himself as self- injury, banging the head and also at others. Active eratomania (personis driven to make overt sexual advances to other people) the patients are restless, cunning 
and deceptive in nature. They have tendency to become violent and desires to dance which relieves their complaints. It affects nervous system. Extreme restlessness, even though walking aggravates yet he must keep in constant motion. Hysterical epilepsy. Intense sexual excitement. Generally tarantula worse from motion, contact, touch of affected parts, noise, change of weather. Better: outdoors, music, rubbing affected parts. Complementary: to Ars. alb

\section{Remedy: Veratrum Album (Melanthaceae)}

Adapted to persons with extreme coldness, blueness, and weakness. As the child enters the clinic he / she wanders from one place to a different places, their parents complains that they always talks about the faults of the others and curses. Tendency to chop and tear dresses and other things into small pieces. Frequent lier and never speaks the reality. Inquisitive about religious matter and malingering after religious excitement. Increased concupiscence, kisses everybody, exposes his/her genitalia. Adapted to persons with extreme coldness, blueness, and weakness. Cold perspiration on the forehead with nearly all complaints. Vomiting, purging, and cramps in extremities. Coprophagia violent mania alternates with silence and refusal to speak. Generally the complaints are Worse: in the dark, wet, cold weather. Better: walking and heat ${ }^{[30,31]}$.

\section{Conclusion}

Conduct Disorderis most frequently diagnosed childhood behavior disorder with symptoms of aggressiveness, violence, theft and violation of rules. The $C D$ has to be diagnosed at early stage to avoid the progression of disease into other adult psychiatric disorder like personality disorder, substance abuse, pervasive psychosexual disorders which end in antisocial behavior. Although the symptoms like violence, aggression and impulsivity and other acute emergency conditions are well managed with conventional system, the complete recovery of illness needs prolonged medication without adverse medication effects. Homoeopathy the personalized medicine with ultra-diluted potentised medicinal substances will be effective to bring complete remission of illness on prolonged medications. Based on the disease symptoms remedies like Hyos, Bell, Stramonium, Nux vomica, tarantula portraits towards effective homoeopathic management in conduct disorder.

\section{Acknowledgement}

I Acknowledge Dr. K.C. Muraleedharan Officer in charge, Dr. R. Sitharthan Principal and Dr. N.D. Mohan, HOD Dept. of Psychiatry and all other faculties of NHRIMH for their support and encouragement at all times.

\section{References}

1. Benjamin James Sadock et al., Kaplan and Sadock's synopsis of psychiatry behavioral sciences / clinical psychiatry, eleventh edition; wolters kluwer updated with DSM -5.

2. Reem Ghandour M, Dr, Laura Sherman J et al. Prevalence and Treatment of Depression, Anxiety, and Conduct Problems in US Children; J Pediatr 2019;206:256-267.e3. doi:10.1016/j.jpeds.2018.09.021

3. Morcillo et al. Parental familism and antisocial behaviors: development, gender and potential mechanisms; J Am Acad Child Adolesc Psychiatry 2011;50(5):471-479. doi:10.1016/j.jaac.2011.01.014.
4. Laura Wesseldijk W, Meike Bartels et al. Genetic and environmental influences on conduct and antisocial personality problems in childhood, adolescence, and adulthood; Eur Child Adolesc Psychiatry 2018;27:1123-1132.

5. Magdalena Cerda, Melissa Tracy et al. Comorbidity Among Depression, Conduct Disorder, and Drug Use From Adolescence to Young Adulthood: Examining the Role of Violence Exposures $\mathrm{J}$ Trauma Stress 2011;24(6):651-659.

6. Comorbidity of conduct disorder and personality disorders in an incarcerated juvenile population; The American Journal of Psychiatry; Published Online: 1 Apr 2006 https://doi.org/10.1176/ajp.150.8.1233.

7. Biederman J, Newcorn J, Sprich S. Comorbidity of attention deficit hyperactivity disorder with conduct, depressive, anxiety, and other disorders. Am J Psychiatry 1991;148:564-577.

8. Alexandra Burt S, Brent Donnellan M et al. Age-ofonset or Behavioral Sub-types? A Prospective Comparison of Two Approaches to Characterizing the Heterogeneity within Antisocial Behavior; J Abnorm Child Psychol 2011;39(5):633-644. doi:10.1007/s10802-011-9491-9.

9. Paul Frick J. Developmental pathways to conduct disorder: implications for serving youth who show severe aggressive and antisocial behavior; Psychology in the Schools 2004, 41(8).

10. Robins LN. Deviant children grown up: a sociological and psychiatric study of sociopathic personality. Baltimore (MA): Williams and Wilkins 1966.

11. Farrington DP, Wikstrom PO. Criminal careers in Lo don and Stockholm: across- national comparative study. In: Weitekamp, EGM, Kerner HJ, editors. Cross national longitudinal research on human development and criminal behavior. Boston (MA): Kluwer- Nijhoff 1994, 65-89.

12. Vitaro F, Tremblay RE, Bukowski WM. Friends, friend ships, and conduct disorders. In: Hill J, Maughan B, editors. Con duct disorders in child hood and adolescence. Cambridge child and ado les cent psychiatry. New York (NY): Cam Bridge. University Press 2001, 346-78.

13. Capaldi DM, Patterson GR. Canviolent of fenders be distinguished from frequent Offenders? Prediction from childhood to adolescence. Journal of Research in Crim and Delinquency 1996;33:206-31.

14. American Psychiatric Association, Diagnostic and statistical Manual of Mental Disorders, Fifth edition; American Psychiatric Association publishing, 470.

15. Taylor S, Klein L, Lewis B, Gruenewald T, Gurung R, Updegraff J. Sex differences in biobehavioral responses to threat: Reply to Geary and Flinn Psychological Review 2002;109:751-753.

16. Meyer-Lindenberg A, Buckholtz J, Kolachana B, Hairi A, Pezawas L, Blasi G et al. Neural mechanisms of genetic risk for impulsivity and violence in humans. [Electronic version]. Proceedings for the national academy of sciences. Early edition 2006, 1-6.

17. Caspi A, McClay J, Moffitt T, Mill J, Martin J, Craig I et al. Role of genotype in the cycle of violence in maltreated children. Science 2002;297:851-853.

18. Rajesh Sagar, Bichitra Patra N. Clinical practice Guidelines for the management of conduct disorder; 
Indian J Psychiatry 2019;61:270-6.

19. Graeme Fairchild et al. Brain Structure Abnormalities in Early-Onset and Adolescent- Onset Conduct Disorder, Am J Psychiatry 2011;168:6.

20. Laura Wesseldijk W, Meike Bartels et al., Genetic and environmental influences on conduct and antisocial personality problems in childhood, adolescence, and adulthoodEur Child Adolesc Psychiatry 2018;27:11231132. https://doi.org/10.1007/s00787-017.

21. Petersen IT, Bates JE, Dodge KA, Lansford JE, Pettit GS. Describing and predicting developmental profiles of externalizing problems from childhood to adulthood. Dev Psychopathol 2015;27(3):791-818. Doi:10.1017/S0954579414000789.

22. Jan Buitelaar K, Kirsten Smeets C et al., Conduct disorders, Eur Child Adolesc Psychiatry 2013;22(Suppl 1):S49-S54, DOI 10.1007/s00787-012-0361-y

23. Rajesh Sagar, Bichitra Patra N. Clinical Practise Guidelines for the Management of Conduct Disorder; Indian J Psychiatry 2019;61(supp2):271-276.

24. Jessica Hambly L. Pharmacotheraphy of conduct disorder; Challenges, options and future direction; J of Psychopharmacol 2016;30(10):967-75.

25. Pratap Sharan, Tina Gupta. Clinical practise Guidelines for conduct disorder; Indian Journal of Psychiatry 2008, 249-306, 26.

26. Mairead Furlong et al., Behavioral and Cognitive behavioural group - based parenting programmes for early onset conduct problems in children aged 3 to 12 years, Campbell systemic Reviews 2012, 8(1).

27. Stuart Close. The genius of homoeopathy Lectures and Essays on the Homoeopathic philosophy with word index, second edition, B Jain publishers (P) Ltd, 2-3.

28. Samuel Hahnemann, Organon of medicine word index included fifth and sixth combined. Adi BS. Efficacy of homoeopathic medicines in chronic low back pain: A clinical study. International Journal of Alternative and Complementary Medicine 2020, 17-20. Indian dermatology online journal B. Jain Publishers (P) LTD 2014;5(4):535

29. Dr. Patil JD. MD (Hom) Group Study in Homeopathic Materia Medica with quick review flow charts, B. Jain Publishers (P) Ltd.

30. Dr. Phatak SR. Materia Medica of homoeopathic medicines, second edition - revised and enlarged, B. Jain Publishers (P) Ltd.

31. William Boericke, Boericke's New Manual of Homeopathic Materia Medica with Repertory, Third Revised and Augmented edition Based on Ninth Edition, B Jain Publishers (P) Ltd.

32. Vimal Maurya $\mathrm{K}$ et al., Dark Classics in Chemical Neuroscience: An Evidence Based Systematic Review of Belladonna, ACS Chem. Neurosci 2020;11(23):3937-3954. 